\title{
Desafios e perspectivas no processo de publicar
}

A função do conhecimento que se produz é o subsídio a novas tecnologias e aplicações que possam resultar em benefício à saúde humana. Para Pereira Jr. (2007)1, "nos países que não conseguem concatenar o processo produtivo com o sistema de inovações científicas e tecnológicas, ocorre ao invés de um 'círculo virtuoso', um círculo vicioso, no qual a baixa produtividade econômica que impede investimentos em educação e pesquisa científica e tecnológica". Não precisa ser especialista no tema para identificar as restrições impostas por tal panorama no Brasil e em qualquer outro pais. A escassez de editais de fomento à pesquisa afeta a carreira dos pesquisadores, sendo que o nível stricto sensu é a ponta de um iceberg, cuja parte submersa está nos níveis do ensino fundamental e médio com as dificuldades de acesso ao ensino de qualidade nas instituições públicas e privadas. São muitas as pesquisas que podem ser realizadas com foco em temas de relevância para o desenvolvimento econômico, social e humano, cujos resultados possam ser aplicados por meio de mecanismos que serão gerados a partir da leitura e apropriação do conhecimento produzido, sempre a partir de uma boa pergunta de pesquisa oriunda da observação da realidade social e identificação de uma necessidade a ser atendida em cada realidade. Boas pesquisas podem ser realizadas apenas quando houver incentivos e mecanismos que possibilitem sua execução e a aplicação de seus resultados. Esta breve explanação ressalta a importância das publicações acadêmicas e mostra a relevância de sua divulgação em periódicos, não apenas com o intuito de obter pontuação no currículo do pesquisador, mas sobretudo para informar a sociedade dos resultados de estudos bem conduzidos e disponibilizar evidências que poderão, em última instância, cumprir o papel da ciência: contribuir com a qualidade de vida humana. Nesse sentido os periódicos científicos têm uma função fundamental, sem eles não se completa o ciclo iniciado quando projeta e executa uma pesquisa. Para tanto, porém, é preciso colocar em funcionamento uma engrenagem de grande complexidade que envolve um bom sistema de captação de manuscritos para processamento e editoração dos mesmos. Os manuscritos, depois de avaliados, aprimorados e aceitos para publicação, resultam em um produto de qualidade que vai sustentar e alavancar práticas de saúde confiáveis. A revista Fisioterapia em Movimento, desde maio de 2017, conta com a plataforma Scholar One, que tem dado maior controle e visibilidade ao grande número de submissões que recebe. 0 periódico continua prestando seus serviços à sociedade, sem cobrança de qualquer taxa de submissão ou publicação. Nesta nova etapa torna-se ainda mais importante a contribuição de nosso corpo de editores associados e per review, pela qual agradecemos mais uma vez.

Profa. Dra. Auristela Duarte Moser Editora Chefe

\footnotetext{
1 Professor adjunto, Departamento Educação, Instituto de Biociências de Botucatu, Universidade Estadual Paulista (UNESP), São Paulo, SP. J Vasc Bras. 2007;6(4):307-308.
} 
